\title{
Difficulties self-reported of chewing and swallowing by active elderly
}

\author{
Juliana Paula Venites ${ }^{*}$, Francelise Pivetta Roque ${ }^{2}$ and Brasília Maria Chiari ${ }^{1}$ \\ ${ }^{1}$ Department of Speech-Hearing Pathology, Universidade Federal de São Paulo, Brazil \\ ${ }^{2}$ Department of Dysfagia , Univerisidade Federal Fluminense, Brazil
}

\begin{abstract}
The purpose of this study was to compare the presence of difficulties self-reported of chewing and swallowing by active elderly with a group of university adults. In this analytical study of transversal cohort 186 subjects divided into two groups: 93 active elderly from community center for health and leisure activities for people over 60 years old and 93 university adults. The age of the elderly was 63 to 93 years old (mean 72.3) and adults 17 to 45 years old (mean 24.8). Respondents selected by screening answered questions regarding their dental conditions, use of prosthetic implants and difficulties in chewing and swallowing in varying consistencies. The mean of teeth present among adults was 30.6 against 8.7 of the elderly. In the elderly group, there was edentulism in $28 \%$ of respondents. None of them refers to the presence of all teeth. Already in the adult group, edentulism has not been reported and nearly $40 \%$ of them reported the presence of all teeth. Thirty-one point two percent for the elderly reported difficulties chewing against $1.1 \%$ of adults. Swallowing difficulties were statistically prevalent in the elderly group: $21.5 \%$ thin liquid, $4.3 \%$ viscous liquid and $16.1 \%$ dual consistencies against adults group; $39.8 \%$ solids and $34.4 \%$ saliva compared to $1.1 \%$ of adults and $40.8 \%$ pills versus $9.7 \%$ of adults group. These results support the idea that prevention programs, early detection and warning of nutrition and physical consequences of the problems swallowing should be implanted in institutions whose focus is serving the active elderly.
\end{abstract}

\section{Introduction}

The increase in the elderly population is a global reality. It is estimated that in fifteen years the population over the age of 60 years old will add 1.2 billion people. In developing countries like Brazil, this increase is even more significant. According to the comparative data of 1991 and 2010 Census, the total of elderly individuals increased from $5.6 \%$ to $9.7 \%$, unusual increase to all other age groups [1,2].

Understanding aging and its particularities are essential for the structuring of a social support and health in various institutions that serve this population. Aging is a global, multidimensional process that considers not only biological issues but also the psychological and social aspects [3].

For elderly, the concept of health is strongly linked to their degree of autonomy, that is, its ability to establish and implement their own plans. The ability to manage your life without or with minimal assistance is the determining factor for active aging [4].

According to the demographic reason and of the concept of specific health of the elderly, it is possible to understand the current valuation of the shares of primary and secondary prevention in aging policies. Promote physical, mental and social health implies not only socioeconomic gains, but mainly in the maintenance and improvement of the elderly quality of life [5].

As in most areas of human health research, research in geriatrics and gerontology is subjects affected by the pathology, diagnosis and treatment. It is recent research typical phenomena of active aging.

This same scientific path is traveled by speech therapy over the production of its gerontological knowledge. Recent studies showed only about $40 \%$ of active elderly reported some complaints related to swallowing [6,7].
However, these complaints are referred to spontaneously in routine medical appointments. This is likely to be because of active elderly adapt their daily lives to these changes. Perhaps assign them a natural tone, making them part of aging.

On the other hand, swallowing problems are similarly striking in daily life of the elderly. The Neuromuscular aging of the structures involved in swallowing, edentulism and use of poorly adapted prosthesis, among other modifications can cause symptoms such as coughing and choking, making the elderly restricted your food variability $[8,9]$.

This diet can cause weight loss and malnutrition, and reduce food pleasure and interfere in the role of socialization that the act of eating provides [8].

It is worth mentioning that, before any typical disease of aging, focal or degenerative, the swallowing problem can progress to dysphagia, changes in food path that exposes the elderly at risk of malnutrition, dehydration and/or aspiration, disturbance this strongly linked to morbidity and mortality.

Thus, there is the knowledge of possible difficulties in chewing and swallowing of active elderly, contributing as an initial guideline for primary and secondary prevention programs, these actions are fundamental to the maintenance and improvement of their quality of life.

Correspondence to: Juliana Paula Venites, PhD student, Post Graduate Program in Human Communication Disorders, Department of SpeechHearing Pathology, Universidade Federal de São Paulo, Brazil, Tel: 55-1198368-3000, E-mail: jvenites@uol.com.br

Key words: elderly, community, chewing, swallowing, deglutition disorders

Received: May 22, 2017; Accepted: June 08, 2017; Published: June 10, 2017 
The purpose of this study was to compare the presence of difficulties self-reported of chewing and swallowing by active elderly with a group of university adults.

\section{Methods}

It is an analytical study of transversal cohort. It was approved by the Ethics Committee of the Federal University of São Paulo - UNIFESP / EPM under 638 798/201 protocol number.

From March to December 2014, we interviewed 196 subjects divided in two groups:

$\checkmark 93$ active elderly from Community Center for Third Age of the great city of São Paulo (age range 63 to 82 years old);

$\checkmark \quad 93$ adult students from a private university in São Paulo, aged 17 to 45 years old.

It is considered the active concept of aging described by the World Health Organization (WHO) which provides for the active participation of the elderly in social, economic, cultural and civil and low susceptibility to disease and high functional ability (physical and cognitive) to selection of active elderly [10].

Based on this concept, an initial screening was carried out in order to ensure that functional and cognitive capacity of the groups studied were preserved. It held even a short questionnaire to exclude previous communication disorders and swallowing.

For cognitive screening we used the Mini Mental State (MiniMental) and to check for possible losses in functional capacity, we used the functional capacity scale BOMFAQ (Brazilians Older Multidimensional Functional Assessment Questionnaire), designed in the United States and validated for Portuguese [11,12].

In order to detect changes prior communication, there were four issues arising from the Communication Screening proposed by the Federal Council of Speech-Hearing Pathology [13].

Finalizing the selection, the subjects answered four questions related to swallowing. These questions sought to investigate dysphagia symptoms originating from medical conditions other than the presbyphagia (natural aging swallowing).

The subjects were excluded:

$\checkmark$ Mini-mental score lower than the present number of years studied;

$\checkmark$ BOMFAQ scale present score equal to or greater than 17 points;

$\checkmark$ Positive response to any question in the communication screening;

$\checkmark$ Positive response to any question swallowing screening.

Then, the selected respondents were submitted to an interview divided in two instruments search in accordance with the objective.

Before you start this step, the interviewer make some clarification of what is communication and its difficulties, and directed the respondent to think about each question ensuring that there were no right or wrong answers and that they should reflect what judged more true or compatible with your daily life.

For the adult group was asked to opt for appropriate response, even if the question seemed specific to an elderly person.

\section{Sociodemographic, cultural and health characteristics}

It includes the following general data: name, phone number, gender, age, education, profession, former and current occupation, income, problems of self-reported health and cohabitation of the elderly (live alone, with family or others).

\section{Swallowing characteristics}

Two different aspects swallowing respondents were asked: teeth and difficulties with chewing and swallowing. The questions are carried out in the following Table 1 .

All participants were asked to answer yes or no. In order to clarify the respondents questioned the consistency were exemplified by popular foods in the Table 2 .

\section{Procedures}

Interviews were conducted in times of entry and range of activities, both for the group of elderly as for the adults not to harm its activities in the research environment.

The researcher personally performs the dissemination of research in classrooms and environments frequented by respondents. It was also stated in the bulletin panel of data collection sites, a poster inviting the subject to participate in the study and containing forms to schedule the interview (in person or telephone).

To be sought by the subjects, the interviewer:

$\checkmark$ Personal presentation, explaining the research objectives, the absence of risk to their health and ability to be routed to a global clinical assessment if any change is detected or if the interviewee finds it necessary;

$\checkmark$ By accepting to participate in the questionnaire, the interview was conducted immediately if there was availability of the interviewee and the interviewer was scheduled or a suitable time for both;

$\checkmark$ The interview was conducted at a place designated by the institution, without external interference, provided with table and chairs, with favorable acoustic a dialogue;

Table 1. Questionnaire of swallowing characteristics.

\begin{tabular}{|c|c|}
\hline A- Teething & $\begin{array}{l}\text { 01-) Do you have teeth? } \\
\text { 02-) Number of teeth present } \\
\text { 03-) Do you use dental prosthesis? } \\
\text { 3.1-) What type? (upper, lower, partial, complete or implants) }\end{array}$ \\
\hline $\begin{array}{l}\text { B- Chewing and } \\
\text { swallowing } \\
\text { alterations }\end{array}$ & $\begin{array}{l}\text { 04-) Do you have difficulty chewing food? } \\
\text { 05-) Do you have trouble swallowing the pills? } \\
\text { 06-) Do you have difficulty swallowing saliva? } \\
\text { 07-) Do you have trouble swallowing thin liquids? } \\
\text { 08-) Do you have difficulty swallowing viscous liquids? } \\
\text { 09-) Do you have difficulty swallowing solid food? } \\
\text { 10-) Do you have difficulty swallowing pasty food? } \\
\text { 11-) Do you have difficulty swallowing soft pieces? } \\
\text { 12-) Do you have difficulty swallowing dual consistencies? }\end{array}$ \\
\hline
\end{tabular}

Table 2. Examples of consistencies offered to elucidate the respondents.

\begin{tabular}{|c|c|}
\hline Consistency & Example \\
\hline Thin Liquid & Water, coffee, juice \\
\hline Viscous Liquid & Yogurt. Juice concentrates \\
\hline Pasty Food & Porridge, mashed potatoes \\
\hline Soft pieces & Cooked vegetables and meat softened \\
\hline Solids Foods & Flour, biscuit, grains \\
\hline Dual Consistency & Soup with chunks of vegetables, \\
& watermelon \\
\hline
\end{tabular}


It began with the reading and signing of the free and informed consent form, describing the risks, benefits and discomforts, data confidentiality, as well as their rights as participants;

$\checkmark$ It continued with the completion of screening and for those who fulfilled the inclusion criteria, then the interview;

$\checkmark$ The total duration of the approach (reading/signing of the term, screening and interview) was 20 to 60 minutes.

\section{Statistical method}

According to the characteristics of the sample and the purpose of the study, data were tabulated and submitted to a statistical treatment by using the following tests: ANOVA (Analysis of variance), two proportions equality test, Pearson correlation, confidence interval for the mean: it is a technique used when we want to see how much the mean may vary within a certain confidence probability.

This statistical analysis software were used: SPSS V17, Minitab 16 and Excel Office 2010.

\section{Results}

\section{Sociodemographic, cultural and health characteristics}

There was a predominance of females in the 196 individuals interviewed. They characterized $76.3 \%$ of the adult group and $80.6 \%$ of the elderly group, with no statistically significant difference.

Sociodemographic, cultural and health characteristics of respondents are presented in Table 3.

Respondents who reported health problems, 15 adults (16.1\%) and 70 elderly (75.3\%), showed their clinical conditions, as described in Figure 1 .

\section{Swallowing characteristics}

The results were divided into two parts:

Teething: The mean of teeth present among adults was 30.6 against 8.7 of the elderly. In the elderly group, there was edentulism in $28 \%$ of respondents. None of them reported the presence of all teeth. Already in the adult group, edentulism was not reported. Almost $40 \%$ of them reported the presence of all teeth.

In the Figure 2 shows the distribution of the use of prosthesis and implants in the group of active elderly.

The results obtained in the investigation of difficulties chewing and swallowing the elderly compared to adults, can be seen in the Figure 3 .

None of the respondents relates difficulty swallowing of pasty foods and soft pieces.

Table 3. Sociodemographic, cultural and health characteristics of respondents.

\begin{tabular}{|c|c|c|c|}
\hline Variables & Adults $(\mathrm{n}=93)$ & Elderly $(n=93)$ & P-Value \\
\hline & \multicolumn{2}{|c|}{ Mean (standard deviation) } & \\
\hline Age & $24.8( \pm 7)$ & $72.3( \pm 5.1)$ & $<0.001^{*}$ \\
\hline Education (years) & $12.4( \pm 1)$ & $5.6( \pm 3.7)$ & $<0.001^{*}$ \\
\hline \multirow[t]{2}{*}{ Income } & $1.311( \pm 681)$ & $1.954( \pm 979)$ & $<0.001^{*}$ \\
\hline & \multicolumn{2}{|c|}{ n (\%) } & \\
\hline $\begin{array}{l}\text { Previous occupation } \\
\text { Manual } \\
\text { Mid-level non-manual } \\
\text { Top-level non-manual }\end{array}$ & $\begin{array}{c}0(0 \%) \\
93(100 \%) \\
0(0 \%)\end{array}$ & $\begin{array}{c}72(77.4 \%) \\
17(18.3 \%) \\
4(4.3 \%)\end{array}$ & $\begin{array}{l}<0.001^{*} \\
<0.001^{*} \\
0.043^{*}\end{array}$ \\
\hline $\begin{array}{c}\text { Cohabitation } \\
\text { With family } \\
\text { With friends } \\
\text { Alone }\end{array}$ & $\begin{array}{c}83(89.2 \%) \\
4(4.3 \%) \\
6(6.5 \%)\end{array}$ & $\begin{array}{c}66(71 \%) \\
0(0 \%) \\
27(29 \%)\end{array}$ & $\begin{array}{c}0.002^{*} \\
0.043^{*} \\
<0.001^{*}\end{array}$ \\
\hline Health problems & $15(16.1 \%)$ & $70(75.3 \%)$ & $<0.001^{*}$ \\
\hline
\end{tabular}

*Significance level is 0.05

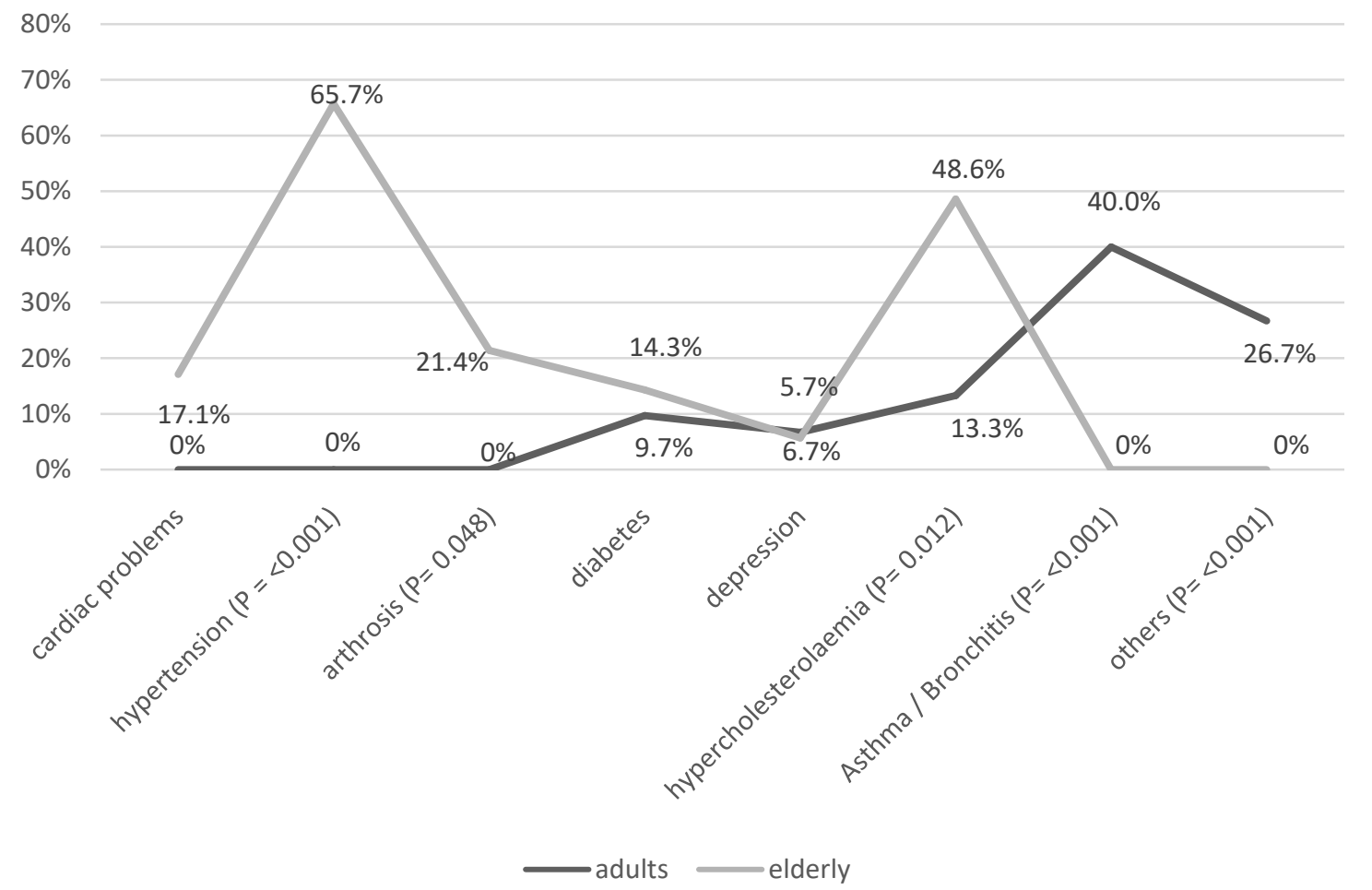

Figure 1. Comparison of the types of health problems reported by adults and elderly groups. 
USE OF DENTAL PROSTHESIS / IMPLANTS

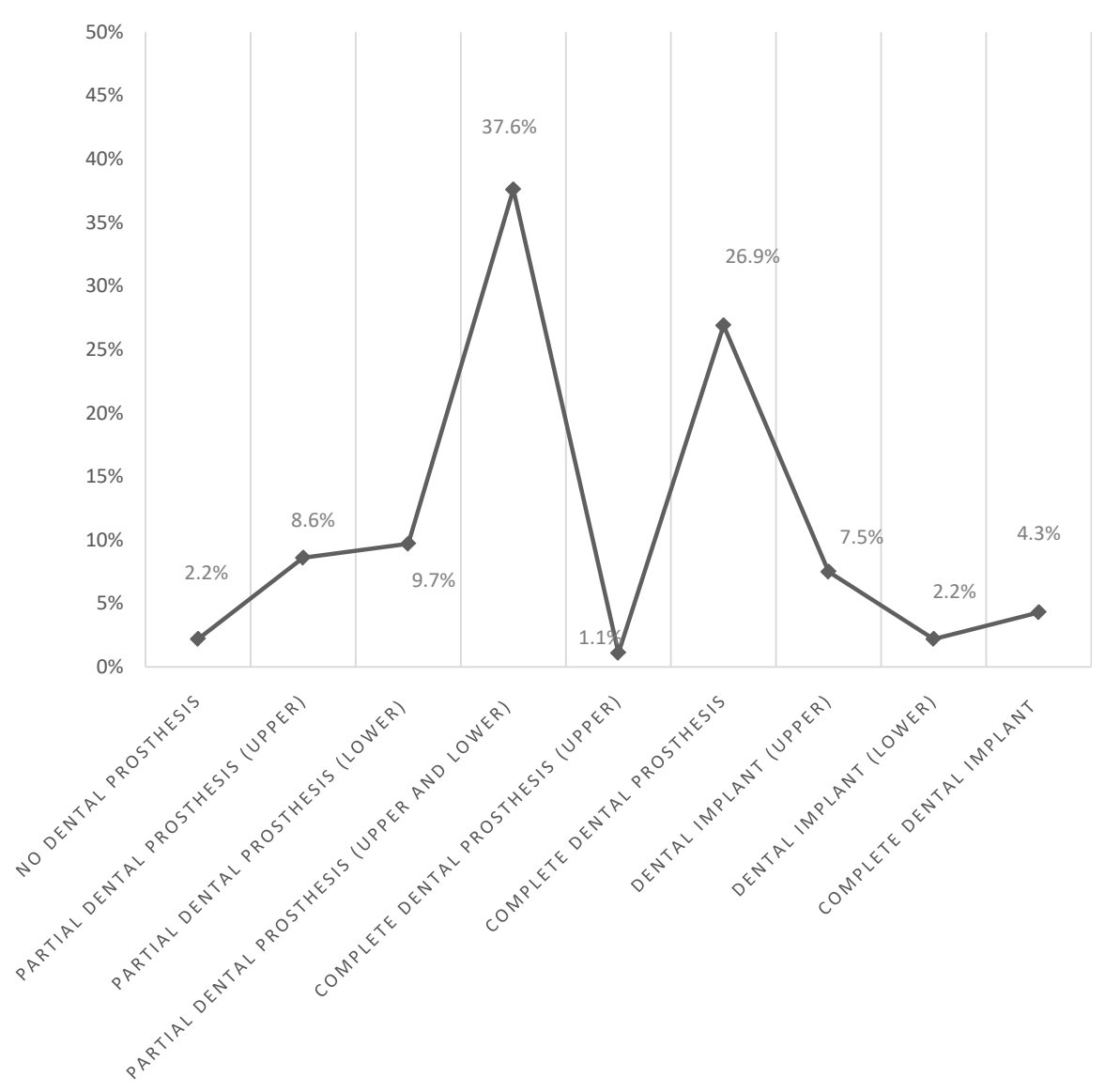

Figure 2. Distribution of the use of prosthesis and implants in the group of active elderly.

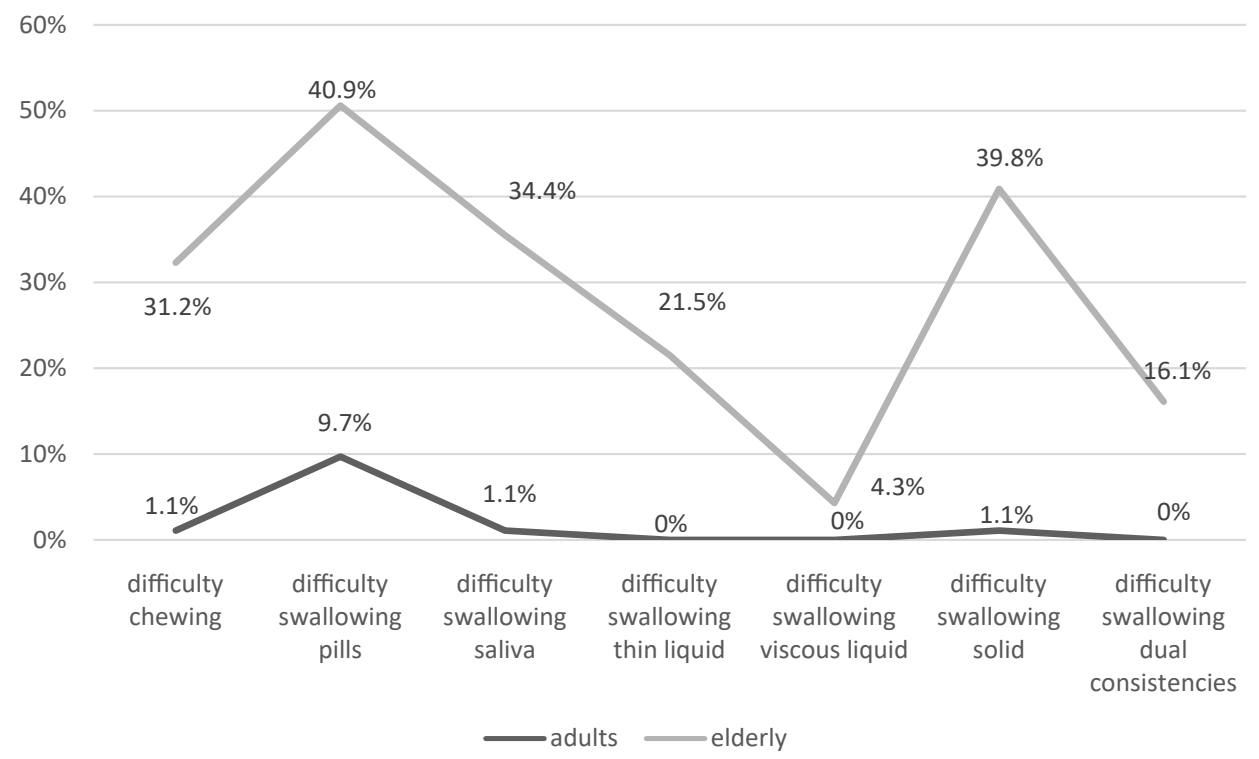

Figure 3. Comparison of chewing and swallowing difficulties self-reported for adults and elderly. 


\section{Discussion}

There was a statistically significant difference between the group of elderly and adults in all aspects. Among the elderly, 28\% reported not having teeth and $72 \%$ reported having just a few; already $39.8 \%$ adults said they had all teeth and some in $60.2 \%$. None of them use prosthesis or dental implants. The use of partial dental prosthesis upper and lower mentioned in $37.6 \%$ of the elderly and complete dental prosthesis upper and lower in $26.9 \%$.

The findings of this study show a substantially better reality when compared with the references of the Ministry of Health of Brazil [14] that shows that $93 \%$ of elderly Brazilians between 65 and 74 years old have lost their teeth (all or some). Similarly, one study evaluated 293 elderly in São Paulo and found a greater number of edentulous (68.3\%) and consequently a greater number of total dental prosthesis users (67\%) [15].

The difficulty of access to dental services in the past and present and the culture that this service should be sought only when there is pain or dental aesthetic damage, contribute for an oral health deficit, which contributes to chewing difficulties in nutritional support, impacting negatively quality of life $[16,17]$.

It is possible that this low percentage among the elderly found in this study is justified by the ease of access to dental services offered by the municipality, which includes in addition to the treatment itself, prosthesis donation and oral health campaigns in own senior center they attended.

Even enjoying good physical and mental health, independence in activities of daily living and the absence of previous complaints that swallowing was found statistically significant difference by asking to active elderly and adults about difficulties for food (chewing and swallowing).

One hundred seventeen healthy elderly American residents of the community were interviewed, and $38 \%$ of them reported some symptom or indication of dysphagia, such as increased feeding time, the presence of cough and feeling of standing food, quite similar content to those for the elderly this research in variables chewing, difficulty swallowing tablets, saliva and solids [18].

The findings thin liquid, viscous liquid and saliva agree on Japanese and English studies who interviewed approximately 1313 and 635 elderly and found complaints of dysphagia in $13.8 \%$ and $11.4 \%$ of participants [19,20].

Although natural aging swallowing, named presbyphagia occurs differently in each individual it is known that the action of time cause structural and functional alterations of swallowing. Changes in muscle composition (change of fiber and enzymes), decreased strength and mobility of the stomatognathic system and the amount of saliva lead to changes in the consistency of foods, often attributed as a preference and not difficulty [8,21-23].

The findings of this research and international findings point to an important index of swallowing difficulties in healthy elderly.

These numbers become even more relevant associated information to another panorama: the face of an acute clinical, neurological, infectious or systemic, elderly who have difficulty swallowing can become fragile, a condition that increases the complications rate as aspiration pneumonia, malnutrition and dehydration [3,19,24,25]. On the other hand, the Brazilian Ministry of Health published in 2010 a booklet of "Healthy eating for the elderly" [26], providing basic guidelines of care in the purchase, preparation and storage of food and other measures that assist in food. However, does not mention the occurrence of symptoms of dysphagia or the possibility of swallowingrelated problems.

Prevention programs, early detection and warning of nutrition and physical consequences of swallowing problems should be developed and widely disseminated in institutions whose focus is the senior care in both public and private spheres, as already noted a positive impact on intervention speech therapy in elderly at risk of dysphagia $[27,28]$.

These preventive actions could minimize the impact of difficulties in chewing and swallowing before a health picture of weakening, focal neurological disorders, dementias, Parkinson's disease, infections and delirium, prolonging an oral food without the risk of aspiration and malnutrition.

\section{Conflicts of interest}

We have no conflict of interest to declare.

\section{References}

1. Veras RP, Ramos LR, Kalache A (1987) Growth of the elderly population in Brazil transformations and consequences in society. Rev Saude Publica 21: 225-233. [Crossref]

2. IBGE - Fundação Instituto de Geografia e Estatística. Síntese de Indicadores Sociais Dados da internet. Disponível em www.ibge.gov.br.

3. Carvalhaes Neto N (2011) Envelhecimento bem sucedido e envelhecimento com fragilidade - In: Ramos LR; Cendrolo M S (org) Guias de Medicina Ambulatorial de Hospitalar da UNIFESP-EPM. 2 ed. pag 9-2, 6. SP Manole. Maio.

4. Ramos LR, Simões E, Albert MS (2001) Dependency on daily living and cognitive impairment strongly predicted mortality among urban elderly residents in Brazil: a twoyear follow up. JAGS 49: 1168-1175. [Crossref]

5. Unfer B, Braun KO, Ferreira ACO, Ruat GR, Batista AK (2011) Challenges and barriers to quality oral care as perceived by caregivers in long-stay institution in Brazil. Gerodontology 29: 324-330. [Crossref]

6. Silva MLP, Ramos TMS, Aguiar GM, Nunes NMNP, Trindade Filho EM, et al. (2010) Impacto Psicossocial das Queixas de Deglutição Comparado às de Audição e Linguagem em Idosos Ativos; Anais: $18^{\circ}$ Congresso Brasileiro de Fonoaudiologia, Curitiba.

7. Chiossi JS, Roque FP, Goulart BN, Chiari BM (2014) Influence of voice and hearing changes in the quality of life of active elderly individuals. Cien Saude Colet 19: 33353342. [Crossref]

8. Suzuki HS, Nasi A, Ajzen S, Bilton T, Sanches EP (2006) Avaliação clínica e videofluoroscópica de pacientes com distúrbios de deglutição - estudo comparativo de dois grupos etários: adultos e idosos. Arquivos de Gastroenterologia 43.

9. Shapior J, Downey L (2003) The evaluation and management of swallowing disorders in the elderly. Geriatric Times 4: 1789-1799.

10. Organização Mundial de Saúde. Cartilha - Envelhecimento ativo Disponível em: http:// bvsms.saude.gov.br/bvs/publicacoes/envelhecimento_ativo.pdf

11. Nitrini R, Caramelli P, Bottino CMC, Damasceno BP, Brucki SMD, Anghinah R (2005) Diagnóstico da Doença de Alzheimer no Brasil - Avaliação Cognitiva e Funcional: Recomedações do Departamento Científico do envelhecimento da Associação Brasileira de Neurologia. Arq. Neuropsicol 63-A3: 720-727.

12. Ramos LR, Goihman S (1989) Geographic stratification by socio-economic status: Methodology from a household survey with elderly people in São Paulo, Brazil. Rev Saúde Pública 23: 478-492.

13. CRFa - Conselho Federal de Fonoaudiologia. Manual de procedimentos em Fonoaudiologia. 2012 Disponível em: www.fonoaudiologia.org.br/cffa/index.php/ guias-e-manuais/.

14. Ministério da Saúde - Política nacional de saúde bucal - PDF Disponível em http:// conselho.saude.gov.br/web.comissoes/cisb/doc/politica.nacional.pdf

15. Carneiro RMV, Silva DD, Sousa MLR, Wada RS (2005) Saúde bucal de idosos institucionalizados, zona leste de São Paulo. Cad Saúde Pública 21: 1709-1716. 
16. Brunetti RF, Montenegro FLB (2002) Paladar In: Brunetti RF, Montenegro FLB. Odontogeriatria - Nocões de interesse clínico. Artes médicas. p.480.

17. Barbosa BR, Almeida JM, Barbosa MR, Rossi-Barbosa LA (2014) Evaluation of the functional capacity of the elderly and factors associated with disability. Cien Saude Colet 19: 3317-3325. [Crossref]

18. Roy N, Stemple J, Merril RM, Thomas L (2007) Dysphagia in the elderly: preliminary evidence of prevalence, risk factors, and socioemotional effects. Annals of otology, rhinology \& laryngology 116: 858-865. [Crossref]

19. Kawashima K, Motohashi Y, Fujishima I (2004) Prevalence of dysphagia among community-dwelling elderly individuals as estimated using a questionnaire for dysphagia screening. Dysphagia 19: 266-271. [Crossref]

20. Holland G, Jaysekeran V, Pendleton N, Horan M, Jones M, Hamdy S (2011) Prevalence and symptom profiling of oropharyngeal dysphagia in a community dwelling of an elderly population: a self-reporting questionnaire survey. Dis Esophagus 24: 476-480. [Crossref]

21. Menasria F, Lakroun S, David JP (2013) Deglutition disorders in elderly patient. Soins Gerontol 11-14. [Crossref]
22. Miura H, Hara S, Yamasaki K, Usui Y (2012) Relationship between chewing and swallowing functions and health-related quality of life. Oral health care 23: 10-16.

23. Yoshikawa M, Yoshida M, Nagasaki T, Tanimoto K, Tsuga K, et al. (2005) Aspects of swallowing in healthy dentate elderly persons older than 80 years. J Gerontol A Biol Sci Med Sci 60: 506-509. [Crossref]

24. Turner MD, Ship JA (2007) Dry mouth and its effects on the oral health of elderly people. J Am Dent Assoc 139: 252-253. [Crossref]

25. Keller, H, Chambers L, Niezgoda H, Duizer L (2012) Issues associated with the use of modified texture foods. J Nutr Health Aging 16: 195-200. [Crossref]

26. Ministério da Saúde: "Alimentação saudável para a pessoa idosa" Cartilha de Orientação para profissionais de saúde. Disponível em http://bvsms.saude.gov.br/bvs/ publicacoes/alimentacao_saudavel_idosa_profissionais_saude.pdf

27. Sura L, Madhavan A, Carnaby G, Crary MA (2012) Dysphagia in the elderly: management and nutritional considerations. Clin Interv Aging 7: 287-298. [Crossref]

28. Takeuchi K, Aida J, Ito K, Furuta M, Yamashita Y, et al. (2014) Nutritional status and dysphagia risk among community-dwelling frail older adults. J Nutr Health Aging 18: 352-357. [Crossref]

Copyright: (C2017 Venites JP. This is an open-access article distributed under the terms of the Creative Commons Attribution License, which permits unrestricted use, distribution, and reproduction in any medium, provided the original author and source are credited. 